\title{
Estudio Histológico e Histoquímico del Glande de Pene Humano
}

\author{
FRIDA HUARAZ, YELITZ BRAVO $y^{\prime}$ MARIELENA VILCAROMERO \\ Departamemo de Ciencias Morfológicas. Faculrad de Medicina UNMSM.
}

\begin{abstract}
RESUMEN
OBJETIVO: Contribuir al conocimiento de la estructura histológica del glande humano, sentando las bases para una mayor comprensión de su anatomía microscópica y fisiología. MATERIALES Y MÉTODOS: Se obtuvo glandes de 12 cadáveres de adultos, los cuales fueron procesados y teñidos con Hematoxilina-Eosina, tricrómico de Mallory-Azan y tricrómico de Masson para el estudio de la morfología; imṕregnación argéntica para la observación de fibras y terminaciones nerviosas; ácido peryódico de Schift para la demostración de glucoproteínas y la coloración de aldehido fucsina de Gomori para el estudio de fibras elásticas. RESULTADOS: Se observó que el glande presenta una piel modificada con un epitelio poliestratificado plano ligeramente queratinizado. Para un mejor estudio se dividió el glande en tres regiones histológicas: una distal (punta del glande), una región media y una región proximal, que es la zona cercana al límite con los cuerpos cavernosos del pene. CONCLUSIONES: Hemos encontrado algunas diferencias entre el tejido propio del glande y el tejido que conforma los cuerpos cavernosos y esponjoso del pene.
\end{abstract}

Palabras claves: Pene, Anatomía \& Histología; Técnicas Histológicas; Histocitoquímica.

\section{HISTOLOGICAL AND HISTOCHEMICAL STUDY OF HUMAN GLANS PENIS SUMMARY}

OBJECTIVE: To make a contribution to the knowledge about the histological and histochemical features of human glans penis. MATERIAL AND METHODS: We evaluated 12 specimens, f glans penis obtained from human cadavers. Specimens were stained with Hematoxylin-Eosin, Mallory-Azan trichromic and Masson trichromic for distinguishing morphologic features; argentic staining for neural endings and fibers visualization; periodic acid of Schift for glucoprotein identification and aldehyde-fuchsin for elastic fibers identification. RESULTS: Glans penis exhibited a modified skin with slightly keratinized stratified squamous epithelium. In order to improve the study, glans were divided into three histological areas: distal, middle, and proximal. CONCLUSIONS: We have found some differences between glans tissue as well as the spongy and cavernous bodies penis tissue.

Key words: Penis, Anatomy \& Histology; Histological Techniques; Histocitochemistry.

\section{INTRODUCCIÓN}

El glande, dilatación distal del cuerpo esponjoso del pene, es una parte anarómica esencial por ser la fuente

Correspondencia:

Lic. Frida Huara Lovola

Facullad de Medicina. UNMSM

Ar: Gran 755. Lima I. Peri

E-mail: bibmed@sanfer.mmmsm.edu.pe más importante de impulsos para iniciar el aclo sexual y como tal debe presentar la estructura hiscológica adecuada para cumplir con dicha función $\left({ }^{1-3}\right)$.

Al no encontrar en la literatura una descripción histológica detallada del glande, se ha realizado en el presente trabajo un estudio de su anatomía microscópica. observando que había diferencias entre su estructura histológica y la de los cuerpos cavernosos y esponjoso del pene. Esperamos de esta manera contri- 
buir en el conocimiento de la estructura histológica del glande humano. lo cual sentará las bases para una mayor comprensión de su anatomía microscópica y fisiología. Este (rabajo preliminar servirá de base para futuros escudios de la hislología de glandes de niños y recién nacidos.

\section{MATERIALES Y MÉTODOS}

Los glandes fueron obtenidos de 12 cadáveres de adultos. cuyas edades fluccuaron entre los 18 y 55 años, todos ellos fallecidos por muerte accidental. Las muestras se obtuvieron del Hospital Dos de Mayo durante los años 1996 y 1997.

Los glandes se fijaron en formol al $10 \%$ y Bouin. Se incluyeron en parafina de acuerdo a los mécodos comunes y se hizo cortes seriados de todo el glande a 5 y 6 micras. Se efectuó coloraciones con Hematoxilina de Harris-Eosina (H-E), tricrómico de Mallory-Azan y tricrómico de Masson para el estudio de la morfologia. La técnica de impregnación argéntica se empleó para la observación de fibras y cerminaciones nerviosas. Para el estudio histoquímico, se utilizó el ácido peryódico de Schift (PAS) para la demostración de glucoproteínas y la coloración de aldehído fucsina de Gomori para el estudio de fibras elásticas.

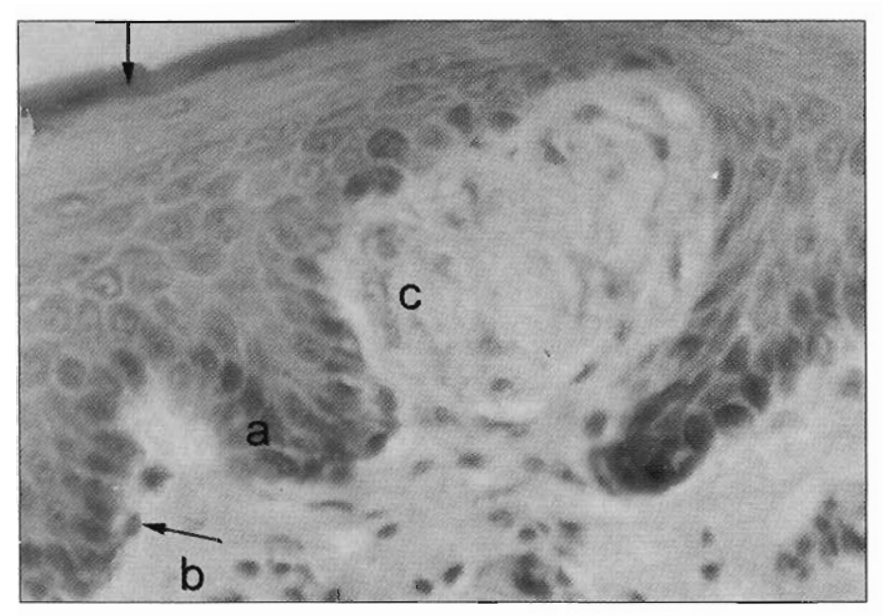

Fig. $N^{\circ}$ 1.- Glande de adulı. Nólese la epidermis ligeramente qucratinizada (flecha). Las células del estrato basal cstán pigmentadas (a), entrc cllas hay melanocitos (flecha). En la dermis se obscrvan vasos sanguíncos (b) y corpúsculos de Mcissner (c). Coloración: Hematoxilina de Harris-Eosina. Escala de reproducción: 100x.

\section{RESULTADOS}

El glande se halla revestido por una piel modificada. con características propias que la diferencian de la piel del resto del cuerpo. La piel del glande presenta un epitelio poliestratificado plano con una ligera queratinización en su superficie. Las células del estrato basal están cargadas de gránulos de melanina, lo que les da una coloración pardo oscura. Entre estas células hay numerosos melanocitos, que con la tinción de $\mathrm{H}$-E presentan un citoplasma clato y un núcleo oscuro central (Figura $N^{\circ}$ 1). A continuación del estrato basal hay cuatro o cinco filas de células poliédricas que corresponden al estrato espinoso. Luego se observan dos o tres filas de células aplanadas, notándose células con gránulos de queratohialina (estrato granuloso). Externamente se ubica el estrato córneo que es muy delgado.

La dermis presenta papilas bastante pronunciadas con crestas papilares muy profundas. Éstas presentan un tejido conectivo laxo con abundante vascularización, hay capilares sanguíneos, linfáticos y vasos de pequeño calibre. En las papilas dérmicas, se localizan terminaciones nerviosas encapsuladas de Meissner (Figura $N^{\circ}$ 1) y bulbos terminales de Krause (Figura $N^{\circ} 2$ ), siendo estos últimos más numernsos. Las terminaciones de Meissner son ovoides, alargadas; en cambio los bulbos terminales de Krause son de forma redondeada. En la dermis

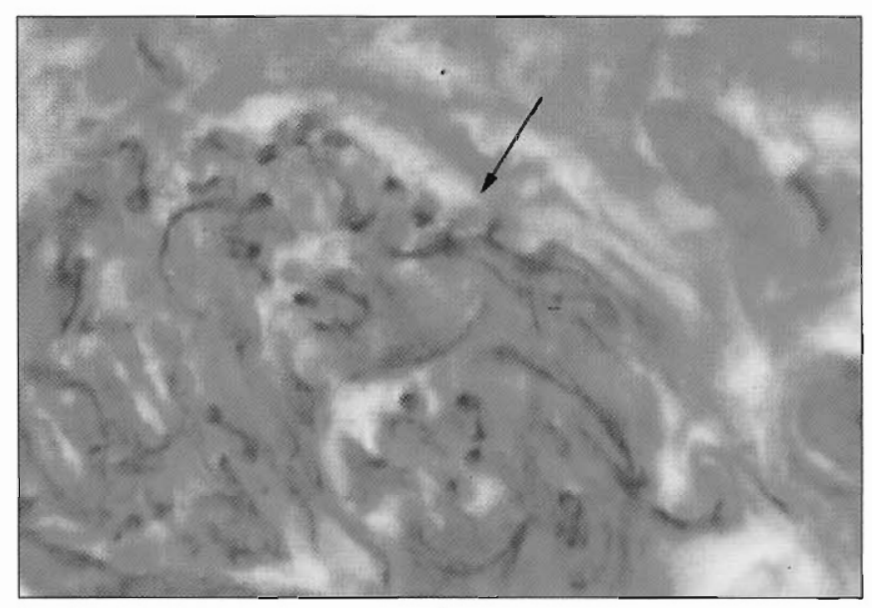

Fig. $N^{\circ}$ 2.- Piel de glande de adulto. Se observa un corpúsculo de Krause (flecha).

Coloración: Impregnación argéntina. Escala de reproducción: $400 x$ 


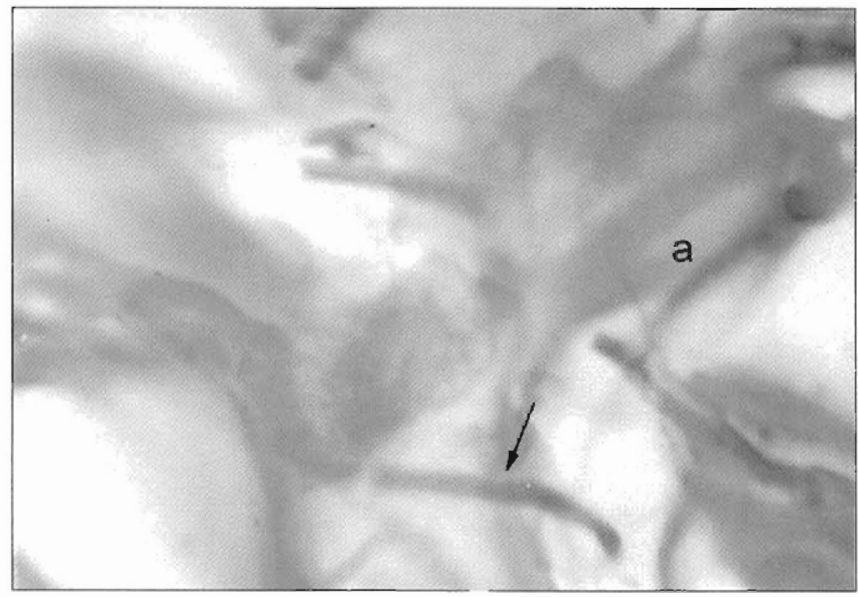

Fig. $N^{\circ}$ 3.- Región discal del glande. Nocar a nivel de las trabéculas. fibras colígenas (a) y fibras elásticas (flecha). Coloración: Aldehído fucsina de Gomori. Escala de reproducción: 100x

reticular hay tejido más denso. con haces de fibras colágenas en diferentes direcciones y numerosas fibras elásticas que dan reacción positiva con la coloración de aldehido fucsina de Gomori (color púrpura). No se ha observado apararo pilosebáceo. ni glándulas sudoríparas.

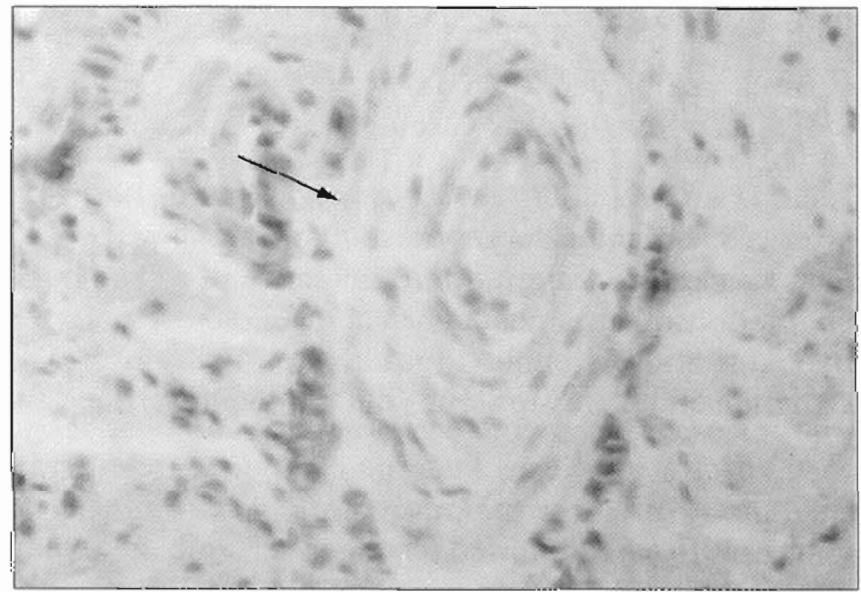

Fig. $N^{\circ}$ 5.- Región distal del glande. Se aprecia un corpúsculo de Vater-Pacini (flecha).

Coloración: Hemacoxilina de Hamis-Eosina Escala de reproducción: $200 x$

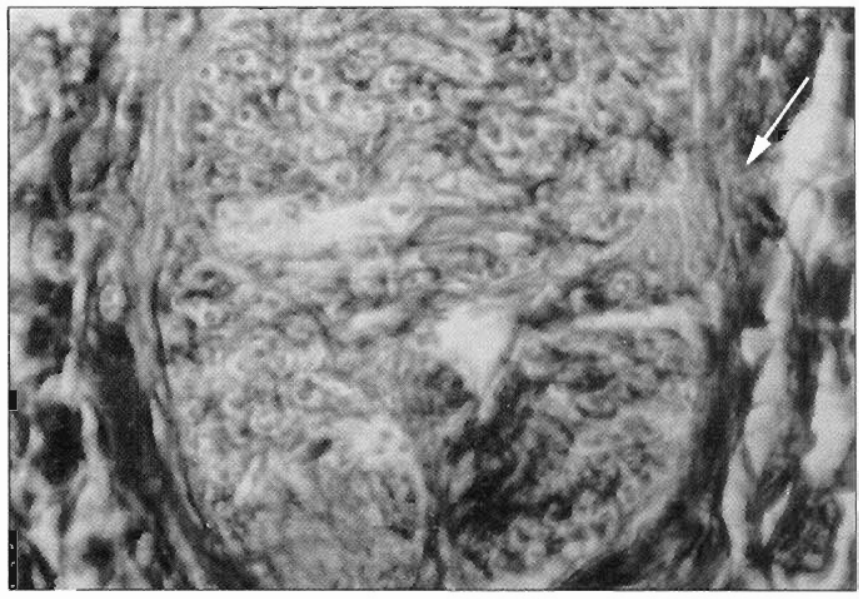

Fig. N4.- Región distal del glande. Se observa un haz de fibras nerviosas (flecha).

Coloración: Tricrómico de Mallory-Azan. Escala de reproducción: $200 \mathrm{x}$

Para un mejor estudio se ha dividido al glande en tres regiones: una región distal (punta del glande). una región media. y una región proximal (corona del glande), que es la zona que limita con los cuerpos cavernosos del pene.

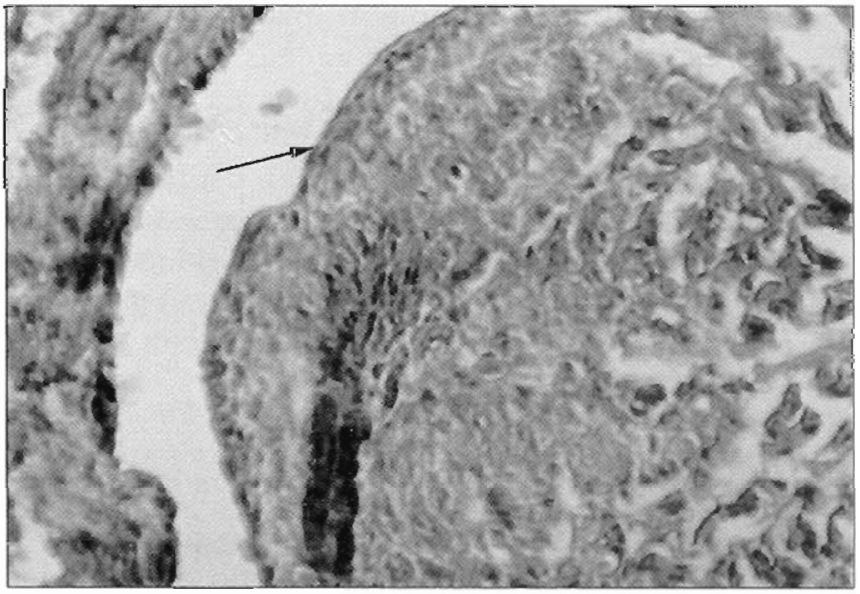

Fig. N6.- Región media del glande. Se observa una vena con fibras musculares en sentido longitudinal en su pared. que le da un aspecto de almohadillado (tlecha). Coloración: Tricrómico de Masson. Escala de reproduccion: 100x 


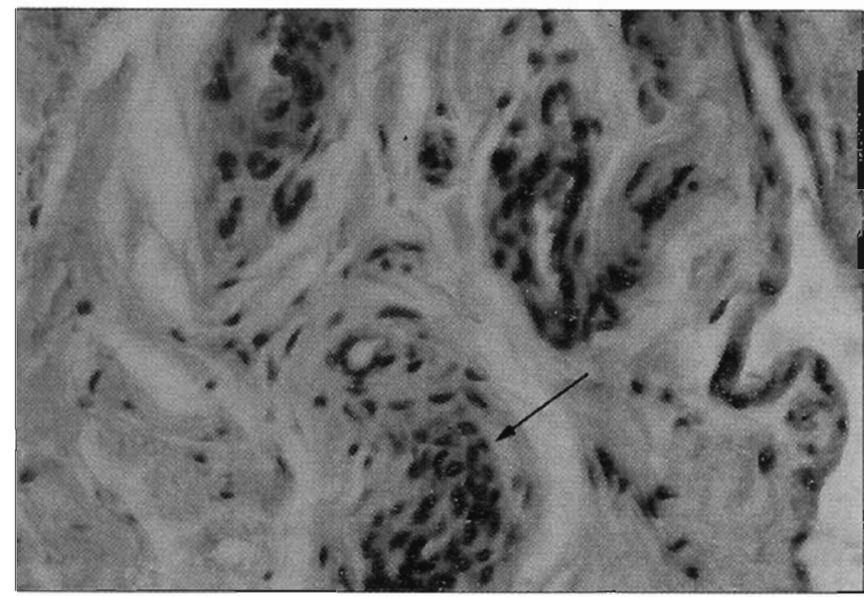

Fig. $N^{\circ} 7 .-$ Región media del glande. Se aprecia las arteriolas helicíneas en las trabéculas (flecha). Coloración: Hematoxilina de Harris-Eosina Escala de reproducción: 100x

En la región distal del glande, por debajo de la dermis reticular, existen haces de fibras colágenas y elásticas de disposición circular. Estas fibras se hallan rodeando al cuerpo esponjoso del pene y se hacen más gruesas y compactas en zonas cercanas a la región proximal del glande, constituyendo aquí una verdadera albugínea. En la región distal del glande, el cuerpo esponjoso está constituido por trabéculas y espacios vasculares. Las trabéculas son anchas y gruesas, con numerosas fibras colágenas, elásticas y algunas fibras musculares lisas (Figura $N^{\circ} 3$ ). También hay numerosos haces de fibras nerviosas que son de diferente tamaño (Figura $N^{\circ} 4$ ), y corpúsculos de Vater-Pacini (Figura $N^{\circ} 5$ ). Asimismo, existen vasos sanguíneos de pequeño calibre. Los espacios vasculares están tapizados por células endoteliales y son de luz estrecha.

En la parte media del glande, las trabéculas son más estrechas, en cambio los espacios vasculares son de luz más amplia. Las trabéculas, al igual que en la punta del glande, constan de un tejido conectivo constituido por fibras colágenas y elásticas, existiendo además una mayor cantidad de fibras musculares lisas. También existen arterias y venas de mediano calibre, y en algunos casos las arterias y las venas se hallan modificadas. Las arterias presentan dos formaciones laterales que sobresalen hacia la luz en forma de almohadillados. Eslas formaciones están constituidas por fibras muscu-

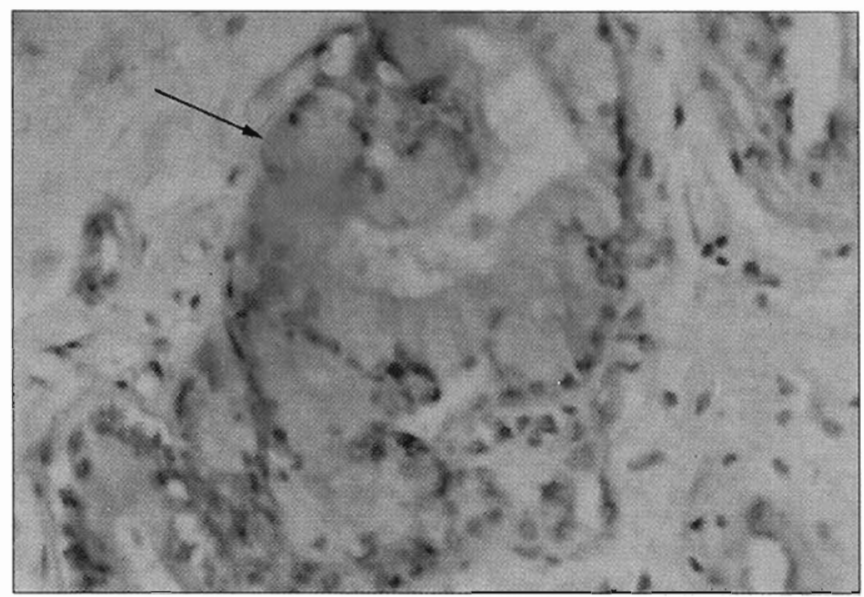

Fig. $N^{\circ}$ 8. - Región proximal del glande. Se distinguen las glándulas de Littré (flecha). Coloración: PAS. Hematoxilina de Harris Escalade reproducción: 100x

Iares lisas longitudinales y tejido conectivo, localizándose inmediatamente por debajo del endotelio. En la zona de la arteria donde no hay almohadillado se deja ver la estructura típica de la arteria. Las venas también presentan por debajo del endotelio una formación constituida por tejido conectivo y fibras musculares lisas longitudinales. Esta formación tiene forma de almohadillado y sobresale hacia la luz (Figura $N^{\circ} 6$ ).

En la región proximal del glande las trabéculas son delgadas y los espacios vasculares son más amplios.

Existen arteriolas de luz muy estrecha llamadas arteriolas helicíneas, que presentan fibras musculares lisas en sentido longitudinal, ubicadas por debajo del endotelio y externamente una capa delgada de músculo liso en sentido circular (Figura $N^{\circ} 7$ ). Estas arteriolas se hallan en las tres regiones del glande descritas.

La uretra atraviesa el cuerpo esponjoso del glande. En la región proximal del glande su epitelio es poliestratificado cilíndrico. A este nivel también desembocan los conductos de las glándulas de Littré, estas glándulas son mucosas y dan reacción positiva con el PAS, sus células se tiñen de color rojo grosella intenso (Figura $N^{\circ} 8$ ).

En la región media y distal del glande, el epitelio uretral es poliestratificado plano no queratinizado, para 
luego transformatse a nivel del meato urinario en poliestratificado plano ligeramente queratinizado. Por debajo del epitelio urecral existe una lámina propia delgada de tejido laxo. donde se observa bulbos terminales de Krause.

\section{DISCUSIÓN}

Los resultados del presente estudio nos demuestran variaciones entre la estructura histológica del glande y la de los cuerpos cavernosos del pene. En la región distal y media del glande hemos descrito que las trabéculas son gruesas y los espacios vasculares son de luz estrecha; en cambio a nivel de los cuerpos cavcinosos y esponjosos del pene dichas trabéculas son más angostas y con los espacios vasculares más a mplios $\left({ }^{*}\right)$.

En las crabéculas del glande hemos descrito fibras colágenas y elásticas. coincidiendo en parte con lo reportado por Hsu y col. $\left({ }^{7}\right)$. quienes describen una capa densa de fibras elásticas. tanto en el glande como en los cuerpos cavernosos del pene. Asimismo, Murakami $\left.{ }^{8}\right)$ realizó un estudio inmunohistoquímico en roedores determinando la presencia de colágeno en el glande.

A diferencia de Cormack ( ${ }^{1}$, quien describe numerosos corpúsculos de Meissner en el glande, nosotras hemos observado escasos corpúsculos, pero en cambio hay predominio de bulbos terminales de Krause tanto en la zona dermal como a nivel de la uretra. Estos corpúsculos sensitivos son para la recepción del frío, pero en el glande su función sería táctil $\left(^{2}\right)$. También se ha descrito la presencia de corpúsculos de Varer-Pacini, cuya función sería de receptores de presión. Asimismo, se han descrito numerosos haces de fibras nerviosas distribuidas en el cuerpo esponjoso del glande.

Teniendo en cuenta que la fuente más importante de impulsos para iniciar el acto sexual masculino es el glandé del pene, se jusififica la presencia de todas estas terminaciones nerviosas sensilivas. Además, HauserKromberger y col. (") en un estudio inmunohistoquímico han demostrado la coexistencia de neuropéptidos. al- gunos de los cuales son: péptido intestinal vasoactivo (VIP), péptido de histamina-metionina (PHM) y neuropéptido Y (NPY), localizados tanto en los cuerpos cavernosos y esponjoso, como en el glande del pene y la urerra. También Sathananthan y col. $\left({ }^{10}\right)$ describen la existencia de sustancia $P$ en los nervios del glande.

Se ha descrito la presencia de algunas fibras musculares lisas en el glande. Al respecto, Costa y col. ("). han descrito en los cuerpos cavernosos del pene fibras musculares lisas que tienen receptores de membrana para agentes adrenérgicos.

De acuerdo a lo expuesto, se puede concluir que existen algunas variaciones histológicas entre las estructuras microscópicas del glande y la de los cuerpos cavernosos y esponjoso del pene.

\section{BIBLIOGRAFÍA}

1) Cormack DHI. Histología de Ham. Eơ. Harla. SA. 9"' edicrón. México 1988.

2) Junqueira Y, Carneiro. Hislología Bárica. Salval Editores. 3" edición. Barcelona. 1993.

3) Laboisier P, Aloui R. The physiology of penile rigidity. Prog Urol 1992: 2(1): 119-27.

4) Gartner LP, Lhiatt J. Hislología. Texio Allas. $1^{\text {ti1 }}$ Ed. Edit McGraw-Hill Interamericana Eüitores S^. México. 1997.

5) Laboisier P, Aloui R. Considerable increase in the perincal arterial flow. secondary to slimulation of the glans penis. Ann Urol París 1993: 27(3): 172-5.

6) Stevens A, Love J. Texio y Allas de Hislología. $2^{d i}$ Ed. Edil Harcourı Bracc. España. 1998.

7) IIsu GL, Brock G. The distribution of clastic fibrous clements within the human penis. Br J Urol 1994: 73(5): 566-71.

8) Murakami R. Immunohistochemical and immunoblot analysis of collagens in the devcloping fibrocartilage in the glans penis in the rat. Acta Morphol Nederl Scand 1987; 25: 279-82.

9) Hauser-Kromberger C, Ilacker GW. Ncuropeptides in the human penis: an immunohislochemical sludy. J Androl 1994: 15(6): 510-20

10) Sathananthan AH, Adaikan PG. Fine siructure of the human corpus cavernosum. Arch Androl 1991: 26:107-17.

11) Costa P, Soulie-Vassal ML. Adrencrgic receptors on smooch muscle cells isolated lirom human penile corpus cavemosum. Am J Urol 1993: 150: 859-63. 